\title{
Cracking the problem of atmospheric ice nucleation: chemically induced fracturing of alkali feldspar makes it a better ice-nucleating aerosol particle
}

\author{
ALEXEI A. KISELEV ${ }^{1}$, ALICE KEINERT ${ }^{1}$, TILIA \\ GAEDEKE $^{1}$, ELENA PETRISHCHEVA ${ }^{2}$ AND RAINER \\ ABART $^{2}$ \\ ${ }^{1}$ Karlsruhe Institute of Technology \\ ${ }^{2}$ University of Vienna \\ Presenting Author: alexei.kiselev@kit.edu
}

Feldspar is a major constituent of magmatic, metamorphic, and sedimentary rocks and due to its ubiquity on the Earths' surface, it is also an abundant constituent of the solid aerosol particles. As such, it plays a decisive role in heterogeneous freezing of supercooled cloud droplets, thus influencing cloud properties and precipitation formation. The mineralogy of feldspar has a crucial effect on its ability to induce freezing of supercooled water. Perthites, which are exsolved feldspars that typically take the form of micron-scale lamellar intergrowth of K-rich and Na-rich alkali feldspar, were found to have the highest IN efficacy among all feldspars [1]. The mechanisms relating the lamellar microstructure and enhanced IN efficacy are not known and are currently debated.

The particularly high ice nucleation (IN) activity of microcline has been attributed to structural similarities between (10-10) prism planes of ice and the (100) planes of alkali feldspar [2]. Due to its high surface energy, the (100) plane rarely appears as a free growing crystal face in natural macroscopic feldspar specimens. However, such surface can be generated by means of chemically induced fracturing. In this study, the gem quality Krich alkali feldspar was shifted towards more Na-rich compositions by cation exchange with an $\mathrm{NaCl}-\mathrm{KCl}$ salt melt at $850^{\circ} \mathrm{C}$, and a system of parallel cracks with an orientation close to (100) was induced. Droplet freezing assay experiments performed on the cation-exchanged feldspars revealed an increase of freezing efficacy with respect to the untreated feldspar. In addition, further annealing at $550^{\circ} \mathrm{C}$ for 64 days lead to exceptionally IN activity. We ascribe this phenomenon to the preferential exposure of crystal surfaces oriented sub-parallel to (100). Parting planes with similar orientation as the chemically induced cracks may be generated in lamellar microstructures resulting from the exsolution of initially homogeneous alkali feldspar, a widespread phenomenon in natural alkali feldspar known as perthite formation. This contribution demonstrates how the natural complexity of rock-forming minerals can have a direct impact on Earth's climate.

[1] Whale, Holden, Kulak, Kim, Meldrum, Christenson \& Murray (2017), PCCP 19(46): 31186-31193.

[2] Kiselev, Bachmann, Pedevilla, Cox, Michaelides, Gerthsen \& Leisner (2017), Science 355(6323): 367-371. 